\title{
DEPARTMENT OF COMMERCE
}

\section{Technologic Papers}

OF THE

\section{BUREAU OF STANDARDS}

S. W. STRATTON, DIRECTOR

\section{No. 125 \\ VISCOSITY OF GASOLINE}

\author{
BY \\ WINSLOW H. HERSCHEL, Associate Physicist \\ Bureau of Standards
}

ISSUED MAY 5, 1919

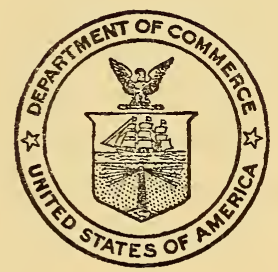

PRICE, 5 CENTS

Sold only by the Superintendent of Documents, Government Printing Office, Washington, D. C.

WASHINGTON

GOVERNMENT PRINTING OFFICE 



\title{
VISCOSITY OF GASOLINE
}

\author{
By Winslow H. Herschel
}

CONTENTS

Page

I. Ubbelohde viscosimeter........................... 3

II. Determination of viscosity in poises by the Ubbelohde viscosimeter.... 5

III. Equations for instruments of standard dimensions $\ldots \ldots \ldots \ldots \ldots \ldots \ldots$ II

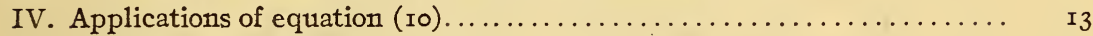

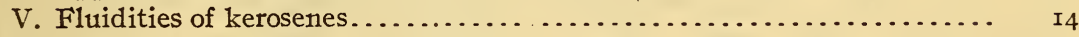

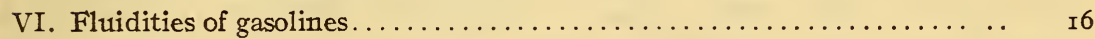

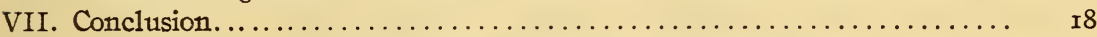

\section{UBBELOHDE VISCOSIMETER}

The short-tube viscosimeters in common use with lubricating oils are not well adapted to measure viscosities approaching that of water, because changes in viscosity have too slight an influence upon the time of flow. For example, with the Engler instrument, the time for gasoline at $10^{\circ} \mathrm{C}\left(50^{\circ} \mathrm{F}\right)$ was found to be 48.7 seconds, and at $50^{\circ} \mathrm{C}\left(122^{\circ} \mathrm{F}\right)$ it was 46.1 seconds. For water the corresponding times were 54.2 and 47.7 seconds. $^{1}$ It will be seen that for smaller changes in temperature it might be difficult to detect any change in viscosity.

According to Ubbelohde ${ }^{2}$ all grades of kerosene show a viscosity of from I to I.05 Engler degrees. Taking the average time for water at $20^{\circ} \mathrm{C}\left(68^{\circ} \mathrm{F}\right)$ as $5^{\mathrm{I}}$ seconds, this statement shows that the time for kerosene is from $5 \mathrm{I}$ to 53.5 seconds, a variation hardly greater than the experimental error.

The Engler, as well as the Saybolt Universal viscosimeter, has an outlet tube only 7 diameters in length, and it is necessary to employ a longer tube in order to obtain an instrument more sensitive to changes in viscosity. A special viscosimeter for illuminating oils was suggested by Engler and constructed by Ubbelohde. Although Lockhart ${ }^{3}$ refers to it as the EnglerUbbelohde viscosimeter, it seems preferable to call it simply the Ubbelohde viscosimeter to more clearly distinguish it from the

1 W. H. Herschel, Bureau of Standards Technologic Paper No. 100, p. 23; 1917. This paper will be referred to subsequently simply as T. P. 100 .

${ }^{2}$ L. Ubbelohde, Petroleum, 4, p. 86r; 1906.

'L. B. Lockhart, American Lubricants: p. 214; 1918. 
Engler instrument for lubricating oils which was improved by Ubbelohde.

The Ubbelohde viscosimeter is similar to the Engler in having a large, shallow container. It differs in the dimensions of the outlet tube, and in being provided with an overflow pipe to determine the initial level of the liquid, instead of gage points as in the Engler instrument. Viscosities are expressed in Ubbelohde degrees, obtained by dividing the time of discharge for the oil by the "water rate" or efflux time for $100 \mathrm{~cm}^{3}$ of water at $20^{\circ} \mathrm{C}$ $\left(68^{\circ} \mathrm{F}\right)$. Since water does not readily wet the surface of the container, especially after it has been previously filled with oil, the overflow can not be used to bring the water level to the correct elevation. The following method is therefore employed in determining the water rate: A sufficient amount of alcohol is poured into the container so that a surplus runs out of the overflow. When the flow has ceased the container is emptied by pulling a skewer out of the top of the outlet tube (just as in starting the flow in an Engler instrument), and the volume of alcohol held in the container, below the level of the overflow, is measured. This same volume of water must be poured into the container when finding the water rate. If an excess of water is used, there is a tendency for it to cling to the overflow pipe, above the level of the liquid in the container, and thus to make the effective head too great.

Table I contains the standard dimensions of the Ubbelohde viscosimeter, ${ }^{4}$ together with the dimensions of two instruments of the Bureau of Standards.

TABLE 1.-Dimensions of Ubbelohde Viscosimeters

\begin{tabular}{|c|c|c|c|c|}
\hline \multirow{2}{*}{ Dimension } & \multirow{2}{*}{ Normal } & \multirow{2}{*}{ Tolerance } & \multicolumn{2}{|c|}{$\begin{array}{l}\text { Bureau of Standards } \\
\text { instruments }\end{array}$} \\
\hline & & & No. 21 & No. 22 \\
\hline & $\mathrm{cm}$ & $\mathrm{cm}$ & $\mathrm{cm}$ & $\mathrm{cm}$ \\
\hline Inner diameter of outlet tube, at top.................. & 0.125 & \pm 0.001 & 0.1311 & 0.1306 \\
\hline Inner diameter of outlet tube, at bottom............... & .125 & \pm .001 & .1282 & .1277 \\
\hline Outside diameter of outlet tube, at bottom, $d_{1} \ldots$ & 1.0 & \pm .05 & .9 & .9 \\
\hline Length of outlet tube, $l \ldots \ldots \ldots \ldots \ldots \ldots \ldots \ldots \ldots$ & 3.0 & \pm .01 & 2.934 & 3.068 \\
\hline Diameter of container, $D \ldots \ldots \ldots \ldots \ldots \ldots \ldots \ldots \ldots \ldots$ & 10.5 & \pm .10 & 10.579 & 10.576 \\
\hline Outside diameter of overflow pipe, $d_{2} \ldots \ldots \ldots \ldots \ldots \ldots$ & ..... & ….... & .67 & .68 \\
\hline Initial head on bottom of outlet tube, $h_{1} \ldots \ldots \ldots \ldots \ldots$. & 4.6 & \pm .01 & 4.545 & 4. 702 \\
\hline Average head, calculated........................... & 3.992 & ........ & 3.950 & 4.104 \\
\hline Water rate, seconds.................. & 200. & \pm 4.0 & 199.9 & 198.6 \\
\hline Capacity of container, cubic centimeter. & & & 132. & 132. \\
\hline
\end{tabular}

1 L. Ubbelohde, loc. cit. Also D. Holde, The Examination of Hydrocarbon Oils, translated by E. Mueller. D. 56 ; 1915 . 
Except for $d_{2}$ Table I contains the corresponding dimensions which are prescribed for the Engler and Saybolt viscosimeters. The average head was calculated from the equation

$$
h=\frac{h_{1}-h_{2}}{\log _{e}\left(\frac{h_{1}}{h_{2}}\right)}
$$

where $h_{1}$ and $h_{2}$ are the initial and final heads, respectively. Since Ioo $\mathrm{cm}^{3}$ are discharged from the viscosimeter during a test, it follows that-

$$
\frac{\pi}{4}\left(D^{2}-d_{2}^{2}\right)\left(h_{1}-h_{2}\right)=100=Q
$$

provided that the surface of the liquid remains in the cylindrical part of the container at the end of run. The depth of this cylindrical part, below the overflow, is $1.3 \mathrm{~cm}$, in an instrument of normal dimensions, and as the surface of the liquid falls a distance $h_{1}-h_{2}$ equal to $1.16 \mathrm{~cm}$, equation (2) will apply. From a comparison of equations (I) and (2) it is evident that $d_{2}$ must be used to determine $h$ and that its value should be specified.

Of less importance is the dimension $d_{1}$ which is supposed to limit the resistance due to surface tension, as with the Engler viscosimeter where the jet spreads out over the whole end surface of the outlet tube. It would appear, however, that no tolerance need be specified with a value of $d_{1}$ as large as I cm, as slight variations in size would have no effect.

\section{DETERMINATION OF VISCOSITY IN POISES BY THE UBBELOHDE VISCOSIMETER}

Holde recommends that a glass viscosimeter should be used if it is desired to obtain viscosity in absolute units; that is, in poises. Ubbelohde, on the other hand, says that he has encountered so many difficulties in using these instruments that they can not be recommended for technical purposes. It is of course realized that the Ubbelohde instrument is not so accurate as, for example, the Bingham viscometer, ${ }^{5}$ but it is believed that for petroleum products, which are not definite chemical compounds, and hence are not strictly reproducible, the Ubbelohde viscosimeter gives sufficiently accurate results.

The purely arbitrary unit, the Ubbelohde degree, should not be confused with the Engler degree, which is another purely arbitrary time ratio. If viscosities are expressed in poises, all confusion is

5 E. C. Bingham and R. F. Jackson, Scientific Paper No. 298, Bureau of Standards, p. 64; 1917. 
avoided, since, within the limits of experimental error, viscosities will have the same value no matter by what instrument they are obtained. It therefore seemed desirable to determine an equation for calculating the viscosity in poises from the time of discharge with the Ubbelohde viscosimeter.

It has been shown in previous papers ${ }^{6}$ that for any efflux viscosimeter in which the pressure causing flow is due wholly to the head of the liquid whose viscosity is to be measured,

kinematic viscosity $=\frac{\text { viscosity in poises }}{\text { density, } g \text { per } \mathrm{cm}^{3}}=A t-\frac{B}{t}$

where

and

$$
A=\frac{\pi g d^{4} h}{\mathrm{I} 28 Q(l+\lambda)}
$$

$$
B=\frac{Q m}{8 \pi(l+\lambda)}
$$

in which $m$ is the coefficient of the kinetic energy correction and $\lambda$ is the "Couette correction" which is necessitated by end effects other than acceleration. $A$ and $B$ may be calculated if $m$ and $\lambda$ are determined, since all other quantities may be taken from Table I.

There are two convenient methods for finding the instrumental constants $A$ and $B$. In Higgins's method the kinematic viscosity divided by the time in seconds $\frac{\mu}{\gamma t}$ is plotted against $\frac{\mathrm{I}}{t^{2}}$. This gives a straight line whose point of intersection with the axis of ordinates gives the value of $A$. The tangent of the acute angle between the line and the axis of abscissas gives the value of $B$.

In Herschel's method $\mu^{1}$ represents the uncorrected viscosity

$$
\frac{\pi g d^{4} \gamma h t}{\mathrm{I} 28 Q l} \text { or } \frac{g d^{2} \gamma h}{32 v l}
$$

where $v$ is the mean velocity of flow. Then $\frac{v d \gamma}{\mu}$ is plotted against $\frac{\mu^{1}}{\mu}$ (the ratio of uncorrected viscosity to the true viscosity obtained under such conditions that $m$ and $\lambda$ are negligible), and finally, for the case when these quantities can not be neglected, they may be obtained by the equations

$$
\begin{aligned}
& m=\frac{3^{2} l}{d \tan \theta} \\
& \lambda=l\left(\frac{\mu^{1}}{\mu}-\mathrm{I}\right)
\end{aligned}
$$

${ }^{6}$ W. H. Herschel, Bureau of Standards, Technologic Paper No. II2, p. 9; 1918. This paper will be referred to subsequently simply as T. P. I12. Proceedings A. S. T. M., 18 (II) p. 363 ; 1918. 
where $\theta$ is the angle between the calibration curve and the axis of abscissas, and $\frac{\mu^{1}}{\mu}$ in equation (7) is the value read at the point where the calibration curve, extended, intersects the axis of abscissas.

TABLE 2.-Times of Discharge for Ubbelohde Viscosimeters

\begin{tabular}{|c|c|c|c|c|c|}
\hline \multirow{2}{*}{ Liquid } & \multirow{2}{*}{$\underset{\text { ture }}{\text { Tempera- }}$} & \multicolumn{2}{|c|}{ Instrument No. 21} & \multicolumn{2}{|c|}{ Instrument No. 22} \\
\hline & & Series 1 & Series 2 & Series 1 & Series 2 \\
\hline \multirow[t]{3}{*}{ Distilled water. . ...................... } & ${ }^{\circ} \mathrm{C}$ & $\begin{array}{r}\text { Seconds } \\
246.6\end{array}$ & $\begin{array}{l}\text { Seconds } \\
\end{array}$ & $\begin{array}{r}\text { Seconds } \\
245.3\end{array}$ & \begin{tabular}{l} 
Seconds \\
\hdashline$\ldots . .$.
\end{tabular} \\
\hline & 10 & 225.3 & ............ & 223.4 & ............ \\
\hline & 15 & 214.5 & ............ & 210.2 & ............ \\
\hline \multirow[t]{7}{*}{ 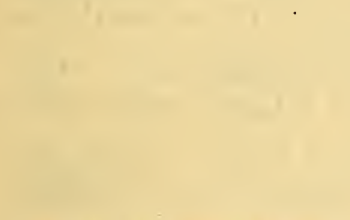 } & 20 & 200.6 & 199.2 & 198.8 & 198.3 \\
\hline & 25 & 190.5 & 190.5 & 189.4 & 190.8 \\
\hline & 30 & 186.0 & 182.1 & 181.6 & 181.7 \\
\hline & 35 & 181.5 & 175.8 & 174.8 & 174.9 \\
\hline & 40 & 172.6 & 171.4 & 170.3 & 168.2 \\
\hline & 45 & 169.6 & 165.5 & 164.3 & 164.8 \\
\hline & 50 & 167.2 & 161.2 & 162.1 & 162.8 \\
\hline \multirow[t]{7}{*}{10 per cent ethyl alcohol solution.. } & 0 & 450.0 & 401.4 & 391.4 & 396.4 \\
\hline & 5 & 370.4 & 338.9 & 331.4 & 336.9 \\
\hline & 10 & 339.6 & 301.7 & 289.6 & 294.1 \\
\hline & 15 & 286.5 & 267.1 & 263.8 & 260.8 \\
\hline & 20 & 256.8 & 242.8 & 240.2 & 240.7 \\
\hline & 25 & 243.0 & 225.5 & 224.8 & 223.2 \\
\hline & 30 & 222.6 & $21 \dot{2.2}$ & 211.4 & 207.2 \\
\hline \multirow[t]{7}{*}{30 per cent ethyl alcohol solution... } & 0 & 784.6 & ....... & 721.8 & ...... \\
\hline & 5 & 608.7 & 602.8 & 579.9 & 593.2 \\
\hline & 10 & 515.5 & 525.8 & 468.1 & 513.8 \\
\hline & 15 & 421.2 & 409.0 & 398.0 & 399.8 \\
\hline & 20 & 364.4 & 345.3 & 347.1 & 343.3 \\
\hline & 25 & 318.0 & 306.0 & 304.2 & 302.7 \\
\hline & 30 & 285.7 & 275.5 & 276.0 & 272.5 \\
\hline \multirow[t]{7}{*}{50 per cent ethyl alcohol solution... } & 0 & 798.8 & ....... & 812.0 & ...... \\
\hline & 5 & 699.6 & 692.4 & 743.5 & 670.0 \\
\hline & 10 & 575.0 & 566.2 & 561.0 & 547.6 \\
\hline & 15 & 485.5 & 512.0 & 496.2 & 501.6 \\
\hline & 20 & 438.4 & 447.5 & 417.4 & 445.6 \\
\hline & 25 & 382.6 & 339.5 & 340.3 & 336.1 \\
\hline & 30 & 316.2 & 319.2 & 304.6 & 306.0 \\
\hline \multirow[t]{7}{*}{20 per cent sucrose solution.. } & 0 & 418.6 & ............... & 425.0 & -........... \\
\hline & 5 & 376.2 & ..................... & 377.5 & ............ \\
\hline & 10 & 330.7 & ................. & 327.1 & -.............. \\
\hline & 15 & 292.5 & 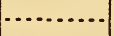 & 289.2 & .............. \\
\hline & 20 & 267.3 & -................... & 263.2 & -............... \\
\hline & 25 & 249.9 & -.................... & 245.7 & - \\
\hline & 30 & 243.7 & $\cdots$ & 234.0 & - \\
\hline \multirow[t]{5}{*}{40 per cent sucrose solution.......... } & 10 & $1,075.0$ & $\cdots$ & $1,140.0$ & (.............. \\
\hline & 15 & 790.0 & (............. & 801.5 & $\therefore \ldots . .$. \\
\hline & 20 & 645.6 & ............. & 649.5 & (............ \\
\hline & 25 & 555.0 & -............ & 581.8 & -........... \\
\hline & 30 & 477.4 & .... & 492.6 & ......... \\
\hline
\end{tabular}


Table 2 gives times of discharge of various liquids of known viscosity. Examination of this table shows that the tests with instrument No. $2 \mathrm{I}$, in series $\mathrm{I}$, showed in nearly every case higher values than in either of the other three columns. It is believed on this account that the tests of series 2 are probably the more accurate.

In plotting Higgins's diagram, Fig. I, from the data of Table 2, the tests with sucrose solutions were omitted. With the Saybolt viscosimeter, ${ }^{7}$ which has a shorter outlet tube, it was found that the sucrose solutions, on account of their higher surface tension, gave an appreciably different calibration curve than that obtained with the alcohol solutions, and that the latter curve was preferable. With the Ubbelohde viscosimeter the effect of differences in surface tension could not be detected, so that there would be no objection to the use of distilled water on account of its high surface tension. Fig. I gives no indication of a bend in the calibration curve. This indicates that the critical velocity was not exceeded, and removes the last possible objection to distilled water as a calibrating liquid.

Fig. 2 shows a Herschel diagram on which only tests with water and sucrose solutions are plotted, the tests with alcohol solutions being omitted to avoid confusion. Here also there is no indication of a bend in the calibration curve. It should be remembered that in Fig. I no correction could be made for variations in dimensions of instruments, so that a greater lack of agreement would be expected between tests on different viscosimeters than in Fig. 2, provided that the dimensions are accurately measured. In previous work with the Engler and Saybolt viscosimeters it was possible to look down the outlet tubes with a microscope and measure the inside diameter at the middle of the tubes. This was not possible with the smaller tubes of the Ubbelohde viscosimeters, and the uncertainty in the assumption, made in calculating the average diameter, $d$, that there was a uniform taper from one end to the other of the outlet tubes is a strong objection to the use of such small, metallic tubes for very accurate measurements. The Herschel method has the advantage that values of $\lambda$ and $m$ are determined, and with increasing knowledge of the possible range of these quantities, their determination will become a check of increasing value. 


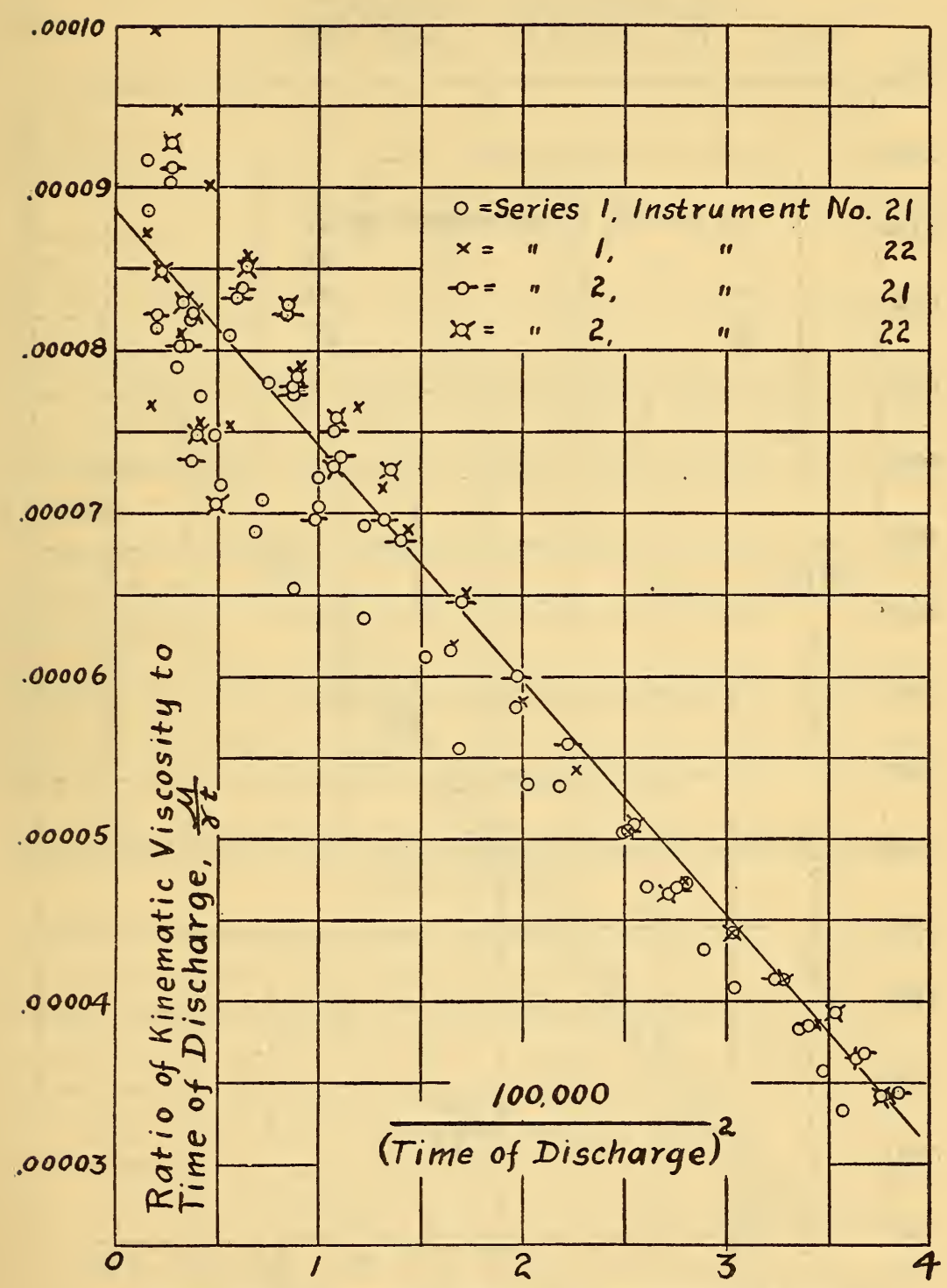

FIG. I.-Calibration curve of Ubbelohde viscosimeter by Higgin's method $106424^{\circ}-19-2$ 
By using the average dimensions of instruments Nos. 2I and 22, from Table I, together with equations (3) to (5), the formula was obtained,

$$
\frac{\mu}{\gamma}=\frac{0.00027173}{3.001+\lambda} t-\frac{3.9789 m}{(3.001+\lambda) t}
$$

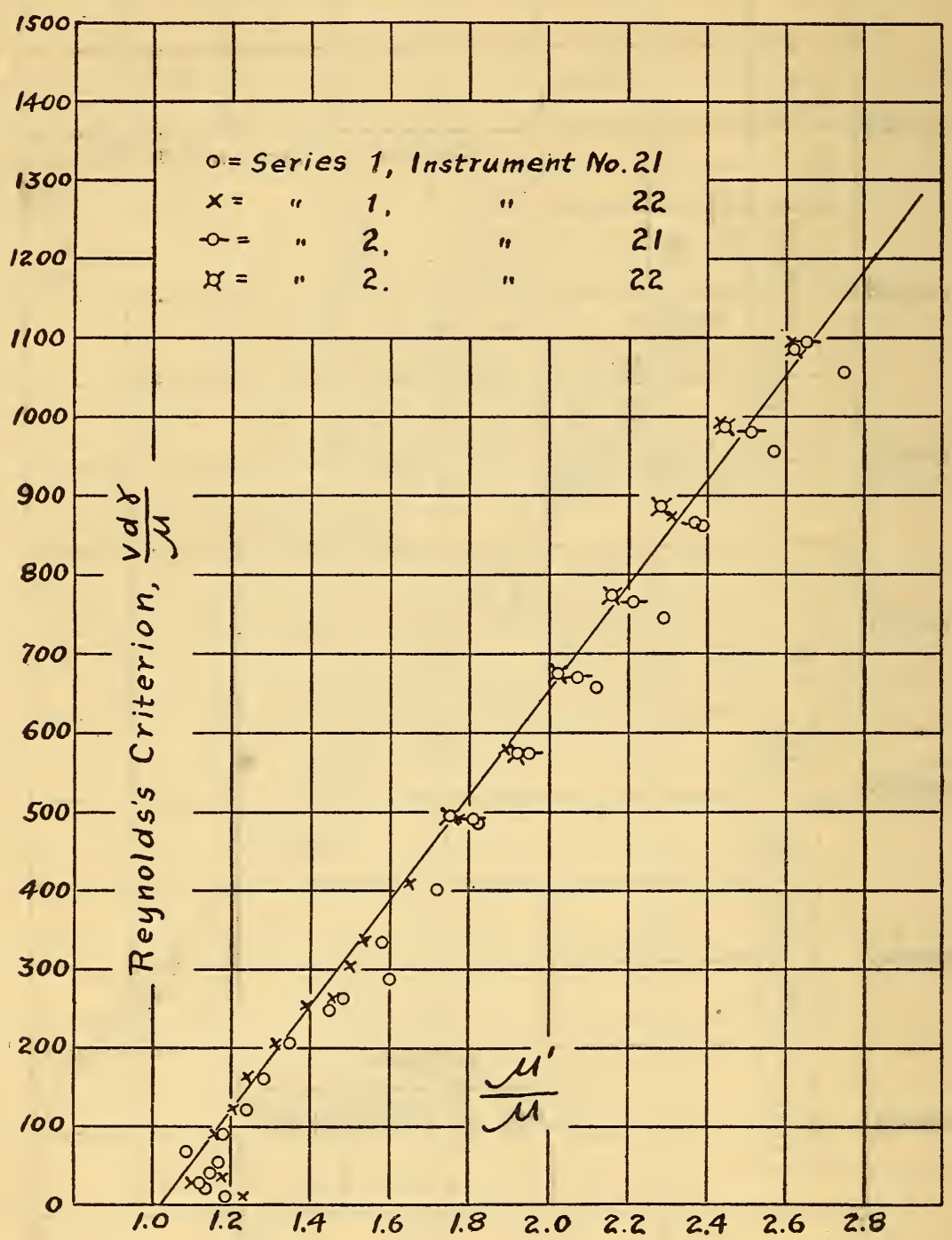

FIG. 2.-Calibration curve of Ubbelohde viscosimeter by Herschel's method

The method of least squares was used for locating the calibration curve on Fig. 2, $m$ and $\lambda$ were determined by means of equations (6) and (7), and finally $A$ and $B$ were calculated from equation (8). Tests on sucrose solutions were not included in these calculations, results of which are given in Table 3 . 
TABLE 3.-Determination of Instrumental Constants by Herschel's Method

\begin{tabular}{|c|c|c|c|c|c|c|c|}
\hline Test series No. & $\frac{l+\lambda}{l}$ & $\lambda$ & $\frac{\lambda}{d}$ & $\tan \theta$ & $m$ & $A$ & $B$ \\
\hline$\frac{1}{2 \ldots}$ & $\begin{array}{l}1.0062 \\
1.0214\end{array}$ & $\begin{array}{r}0.0186 \\
.0642\end{array}$ & $\begin{array}{r}0.144 \\
.497\end{array}$ & $\begin{array}{l}628.7 \\
670.4\end{array}$ & $\begin{array}{l}1.179 \\
1.107\end{array}$ & $\begin{array}{r}0.0000900 \\
.0000887\end{array}$ & $\begin{array}{l}1.554 \\
1.438\end{array}$ \\
\hline
\end{tabular}

Since

$$
t=\frac{\mu}{2 \gamma A}\left(\mathrm{I}+\sqrt{\mathrm{I}+\frac{4 A B}{\left(\frac{\mu}{\gamma}\right)^{2}}}\right)
$$

and $\frac{\mu}{\gamma}$ for water at $20^{\circ} \mathrm{C}\left(68^{\circ} \mathrm{F}\right)$ is equal to 0.010068 , the water rates corresponding to any assumed values of $A$ and $B$ may be easily calculated. The values thus obtained from lines (I) and (2) of Table 3 were, respectively, 198.8 and 197.2 , which agree fairly well with the water rates found experimentally and given in Table $I$.

If series (2) is taken as the more accurate, the equation for calculating viscosity from time of discharge of instruments Nos. 2 I and 22 becomes

kinematic viscosity $=\frac{\text { viscosity in poises }}{\text { density, } g \text { per } \mathrm{cm}^{3}}=0.0000887 t-\frac{\mathrm{I} .438}{t}$ (I0) where $t$ is the time in seconds. The calibration curves of Figs. $\mathrm{I}$ and 2 were drawn to agree with this equation.

\section{EQUATIONS FOR INSTRUMENTS OF STANDARD DIMENSIONS}

It will be noted from Table I that instruments Nos. 2 I and 22 have approximately the normal water rate of 200 seconds, but that the average diameter of the outlet tube is not very close to the specified value of $0.125 \mathrm{~cm}$. Therefore one of these values must be abandoned, and it has appeared preferable to adopt for $d$ a normal value of 0.129 with Ubbelohde's tolerance of \pm 0.001 in order to keep the water rate as close as possible to the specified values. It may be assumed that such slight changes in dimensions will not change $\frac{\lambda}{d}$ nor $m$ and that these values will be the same as found by experiment. Table 4 gives all suggested dimensions, with tolerances in general of the same magnitude as in Table I. 
TABLE 4.-Suggested Dimensions for Ubbelohde Viscosimeters

\begin{tabular}{|c|c|c|c|}
\hline$\cdot$ & $\begin{array}{l}\text { Maxi- } \\
\text { mum }\end{array}$ & Normal & $\begin{array}{l}\text { Minl- } \\
\text { mum }\end{array}$ \\
\hline & $\mathbf{c m}$ & $\mathrm{cm}$ & $\mathrm{cm}$ \\
\hline Average inner diameter of outlet tube, $d . . . .$. . & 0.130 & 0.129 & 0.128 \\
\hline Outside diameter of outlet tube, at bottom, $d_{1} \ldots \ldots \ldots \ldots \ldots \ldots \ldots \ldots . . . .$. & n......... & 1.0 & ...... \\
\hline 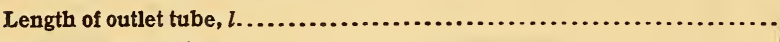 & 3.01 & 3.00 & 2.99 \\
\hline 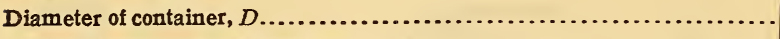 & 10.6 & 10.5 & 10.4 \\
\hline 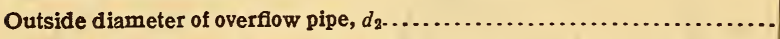 & .71 & .70 & .69 \\
\hline Initial head on bottom of outlet tube, $h_{1} \ldots \ldots \ldots \ldots$. & 4.61 & 4.60 & 4.59 \\
\hline Average head calculated......................... & 4.014 & 3.992 & 3.970 \\
\hline
\end{tabular}

Selecting the dimensions to make the time of discharge a maximum, and with $\frac{\lambda}{d}$ equal to 0.397 and $m$ equal to r.I.O7, the equation was obtained

$$
\frac{\mu}{\gamma}=0.0000834 t-\frac{1.433}{t}
$$

Similarly with normal or mean dimensions

$$
\frac{\mu}{\gamma}=0.0000868 t-\frac{\mathrm{r} .438}{t}
$$

With dimensions tending to give a minimum time of discharge

$$
\frac{\mu}{\gamma}=0.0000903 t-\frac{\mathrm{I} .442}{t}
$$

Table 5 was calculated from equations (II) to (I 3 ) for certain

\begin{tabular}{|c|c|c|c|c|c|}
\hline \multirow{3}{*}{ Llquid } & \multirow{2}{*}{\multicolumn{2}{|c|}{ Temperature }} & \multicolumn{3}{|c|}{ Time } \\
\hline & & & Maximum & Normal & Minimum \\
\hline & ${ }^{\circ} \mathrm{C}$ & ${ }^{\circ} \mathrm{F}$ & Seconds & Seconds & Seconds \\
\hline Distilled water.. & 20 & 68 & 204.8 & 199.0 & 193.8 \\
\hline Do.......................... & 25 & 77 & 195.3 & 190.2 & 185.2 \\
\hline 30 per cent ethyl alcohol solution........... & 20 & 68 & 385.0 & 371.8 & 359.0 \\
\hline 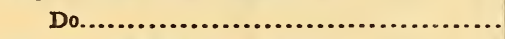 & 25 & 77 & 327.8 & 316.3 & 306.4 \\
\hline 50 per cent ethyl alcohol solution... & 20 & 68 & 417.8 & 403.0 & 389.0 \\
\hline 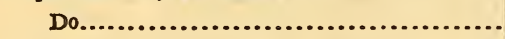 & 25 & 77 & 363.0 & 350.5 & 339.0 \\
\hline
\end{tabular}
suitable calibrating liquids.

TABLE 5.-Times of Discharge Calculated from Dimensions of Table 4

It will be seen that the variation in water rate at $20^{\circ} \mathrm{C}$ is from 205 to 194 , or a variation of I I seconds, as compared with 8 seconds assumed by Ubbelohde. In view of the difficulties of meas- 
uring $d$ accurately, since Rapp's ${ }^{8}$ most accurate method applies only to a glass tube, it would probably be advisable to make $l$ as accurately as possible and then ream out the outlet tube until the time of discharge came within the limits of Table 5 .

\section{APPLICATIONS OF EQUATION (10)}

Care should be taken not to apply equation (Io) above the critical velocity. While there was no evidence from tests that the critical velocity had been reached, it may be estimated as follows. The ratio of length to diameter of the outlet tube being 23.2 it may be expected that the critical velocity would occur when "Reynolds's criterion" $\frac{v d \gamma}{\mu}$ was between 2000 (the value for long tubes) and 800 (the value found for a length of 7 diameters). Assuming that Reynolds's criterion is equal to 1400 at the critical velocity

$$
\frac{\mu}{\gamma}=\frac{v d}{\mathrm{I} 400}=0.0000887 t-\frac{\mathrm{I} .438}{t}
$$

from which, since $v=\frac{400}{d^{2} t}$ and $d=0.1294$,

it may be calculated that $t$ is equal to 55 seconds. Equation (Iо) should therefore be used with caution when the time of discharge is less than this value.

Fig. 3 shows time ratios of the Ubbelohde and Engler viscosimeters according to data given by Lockhart, tests given in Table 2 and others previously published. ${ }^{2}$ The curve has been drawn as calculated by equation (ro) and the Engler equation

$$
\frac{\mu}{\gamma}=0.00147 t-\frac{3 \cdot 74}{t}
$$

for points below the critical velocity where the time, Engler, is 56 seconds or over. For the extreme lower end of the curve, above the critical velocity, it was necessary to use the equation ${ }^{10}$

$$
\frac{\mu}{\gamma}=0.000705 t-\frac{\mathrm{I} .33}{t}
$$

It will be seen that as the time of discharge increases, the time ratio increases, and from the values of $A$ in equations (Io) and (I4) it may be calculated that the time ratio has a constant value of I 6.6 when the kinetic energy correction is negligible.

I. M. Rapp, Physical Review, 2, p. 369; 1913.

'T. P. I00, p. 23.

10 This equation was calculated at the same time as equation (I4), T. P. I00, p. 3 r, but has not previously been published. 


\section{FLUIDITIES OF KEROSENES}

In dealing with liquids of low viscosity it is more convenient to use the fluidity $\frac{I}{\mu}$ instead of the viscosity $\mu$. The temperature-

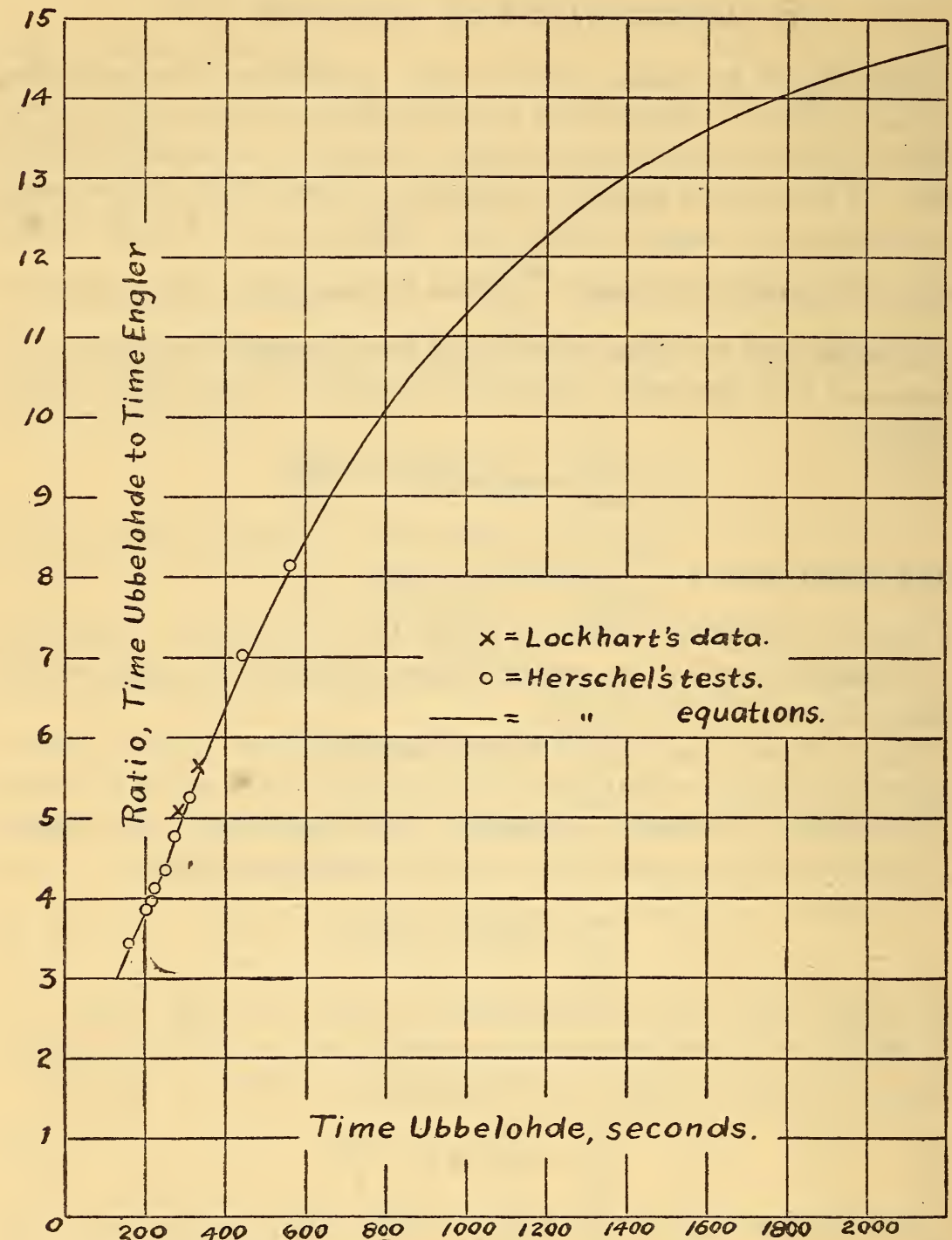

Fig. 3.-Ratio of times of discharge of Ubbelhode and Engler viscosimeters

fluidity curve is more nearly straight than the temperatureviscosity curve, and furthermore by the use of fluidities decimals are avoided. Table 6 shows fluidities of kerosenes calculated by equation (Io) from data of Ubbelohde and Post. ${ }^{11}$ 
The density $\gamma$ in equation (Io) must of course be referred to the density of water at $4^{\circ} \mathrm{C}\left(39.2^{\circ} \mathrm{F}\right)$, and should not be confused with the specific gravity. ${ }^{12}$

TABLE 6.-Fluidities of Kerosenes

\begin{tabular}{|c|c|c|c|}
\hline Authority & Liquid & $\begin{array}{l}\text { Specific } \\
\text { gravity, } \\
15.6^{\circ} \mathrm{C} \\
15.6^{\circ} \mathrm{C}\end{array}$ & $\begin{array}{l}\text { Fluiaiity } \\
\text { at } 20^{\circ} \mathrm{C}\end{array}$ \\
\hline Ubbelohde.......... & Benzine............. & 0.717 & (744.) \\
\hline Do.... & Kerosene C................... & .799 & 61.6 \\
\hline Do................. & 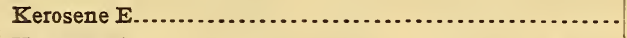 & .799 & $52.8^{\circ}$ \\
\hline Do................. & 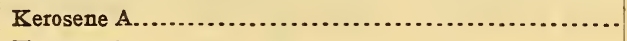 & .808 & 94.9 \\
\hline Do.... & Kerosene B............ & .808 & 70.2 \\
\hline Do.................. & Kerosene $0 . \ldots \ldots \ldots \ldots \ldots$ & .809 & 52.8 \\
\hline Do................. & 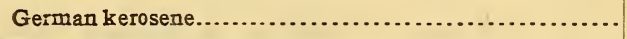 & .816 & 68.5 \\
\hline Do... & 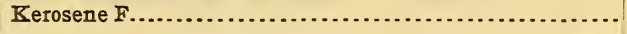 & .817 & 44.2 \\
\hline Do.... & 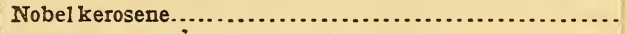 & .823 & 55.3 \\
\hline Post........ & 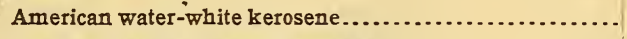 & .790 & 49.3 \\
\hline Do.... & American standard white kerosene................ & .800 & 42.1 \\
\hline Do.... & Russian "meteor" kerosene.......................................... & .800 & 59.7 \\
\hline Do.... & 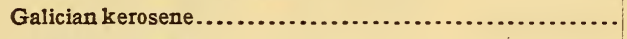 & .809 & 44.3 \\
\hline Do.... & 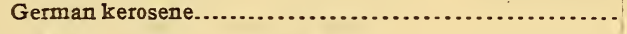 & .810 & 43.6 \\
\hline Do....... & 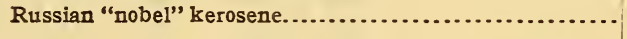 & .824 & 47.3 \\
\hline
\end{tabular}

The fluidity of benzine in the first line of the table is evidently in error. Ubbelohde gives 6.692, which is apparently a misprint for 0.692 as given by Holde. But 744 fluidity, calculated from 0.692 Ubbelohde degrees, is an impossible value, since Bingham ${ }^{13}$ has shown that all the aliphatic hydrocarbons, of which benzine and gasoline are mainly composed, have a fluidity of only about 500 at the boiling point. Part of the error may of course be due to using equation (IO) in the calculation because the critical velocity is exceeded.

It will be observed that there is considerable variation, among the kerosenes, in the fluidity corresponding to a given specific gravity. That this is also true of gasoline is indicated by Dean,,$^{14}$ who says that "specific gravity in itself is of very slight significance in determining the properties of gasoline."

\footnotetext{
12 The following publications of the Bureau of Standards are helpful in making conversions between the Baumé scale, specific gravity and density of oils at different temperatures; Circular I9, Standard Density and Volumetric Tables, p. 43, I916; Circular 57, U. S. Standard Tables for Petroleum Oils, p. 53, and Supplementary Petroleum Oil Table No. 5, 1916; H. W. Bearce and E. I. Peffer, Technologic Paper No. 77, p. I8, I9I6.

13 E. C. Bingham, American Chemical Journal, 43, p. 296; 19ro.

${ }^{14}$ E. WV. Dean, Technical Paper 166, Bureau of Mines, p. II; I9I7.
} 


\section{FLUIDITIES OF GASOLINES}

There is very little published information on the viscosity or fluidity of gasoline. Sorel ${ }^{15}$ gives information from which the viscosity of fuels might be calculated, but all of them are more viscous than water. Brewer ${ }^{16}$ quotes Sorel's table and gives additional data of his own, but his measurements were made with tubes of insufficient length. Table 7 shows fluidities of various gasolines as determined by the Ubbelohde viscosimeter and calculated by equation (го). The gasolines are numbered in the order of their specific gravities. Fluidities calculated from times of discharge less than I55 seconds have been marked with an asterisk (*).

TABLE 7.-Fluidities of Gasolines at Various Temperatures

\begin{tabular}{|c|c|c|c|c|c|c|c|}
\hline \multirow{2}{*}{ Gasoline No. } & \multirow{2}{*}{$\begin{array}{c}\begin{array}{c}\text { Specific } \\
\text { gravity } \\
15.6^{\circ} \mathrm{C}\end{array} \\
15.6^{\circ} \mathrm{C}\end{array}$} & \multicolumn{6}{|c|}{ Temperature } \\
\hline & & $5^{\circ} \mathrm{C}$ & $15^{\circ} \mathrm{C}$ & $25^{\circ} \mathrm{C}$ & $35^{\circ} \mathrm{C}$ & $45^{\circ} \mathrm{C}$ & $55^{\circ} \mathrm{C}$ \\
\hline $1 \ldots$ & 0.757 & 145 & 166 & 193 & 212 & 235 & 262 \\
\hline $2, \ldots \ldots \ldots+\ldots$ & .748 & 130 & 151 & 170 & 194 & 214 & 243 \\
\hline $3 \ldots \ldots . . . . . .$. & .743 & 129 & 156 & 185 & 203 & 227 & (........ \\
\hline $4 \ldots \ldots \ldots$. & .726 & 202 & 233 & 264 & 293 & 324 & $360 *$ \\
\hline 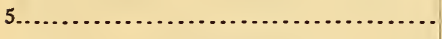 & .722 & 189 & 219 & 244 & 278 & 308 & $342 *$ \\
\hline 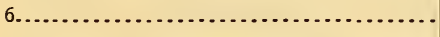 & .717 & 176 & 208 & 239 & 277 & 295 & (........ \\
\hline $7, \ldots \ldots+\ldots, \ldots$ & .716 & 197 & 217 & 256 & 289 & 321 & $341 *$ \\
\hline 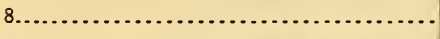 & .708 & 203 & 230 & 257 & 298 & 332 & $360 *$ \\
\hline $9 . \ldots . . . . . . . .$. & .702 & 233 & 261 & 296 & 321 & $358 *$ & $400 *$ \\
\hline $10 \ldots \ldots \ldots \ldots$ & .701 & 230 & 262 & 287 & 333 & $373 *$ & $398 *$ \\
\hline 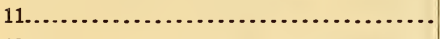 & .699 & 233 & 269 & 306 & 335 & $372 *$ & $423 *$ \\
\hline $12 \ldots \ldots$ & .694 & 251 & 286 & 316 & $354 *$ & $387 *$ & $427 *$ \\
\hline 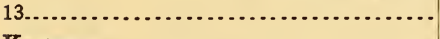 & .680 & 288 & 323 & $365^{*}$ & $413^{*}$ & $441 *$ & $475 *$ \\
\hline 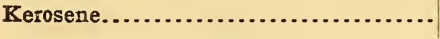 & .813 & 39 & 47 & 61 & 71 & 84 & (.......... \\
\hline
\end{tabular}

Gasolines Nos. 7 and 8 give an example of two fuels with practically the same gravity but greatly differing fluidity. Bingham has shown that the fluidity-vapor pressure curves of the aliphatic hydrocarbons are practically identical. This shows that the vapor pressure or volatility is determined by the fluidity for any of these pure substances, and suggested an investigation of the relation between fluidity and vapor pressure of gasolines which are mainly composed of these hydrocarbons. The experimental determination of the vapor pressure of gasolines has been found to yield widely discordant results, because the nonhomogeneity of the gaso-

${ }^{15} \mathrm{E}$. Sorel, Carbureting and Combustion in Alcohol Engines, translated by Woodward and Preston, p. $165 ; 1907$.

${ }^{16}$ R. W. A. Brewer, Carburetion in Theory and Practice, p. 53; London; 1913. 
lines makes the observed vapor pressure extremely sensitive to slight changes in the experimental conditions.

Fig. 4 was plotted from data of Table 7 , the fluidities of the aliphatic hydrocarbons and of water being taken from the tables

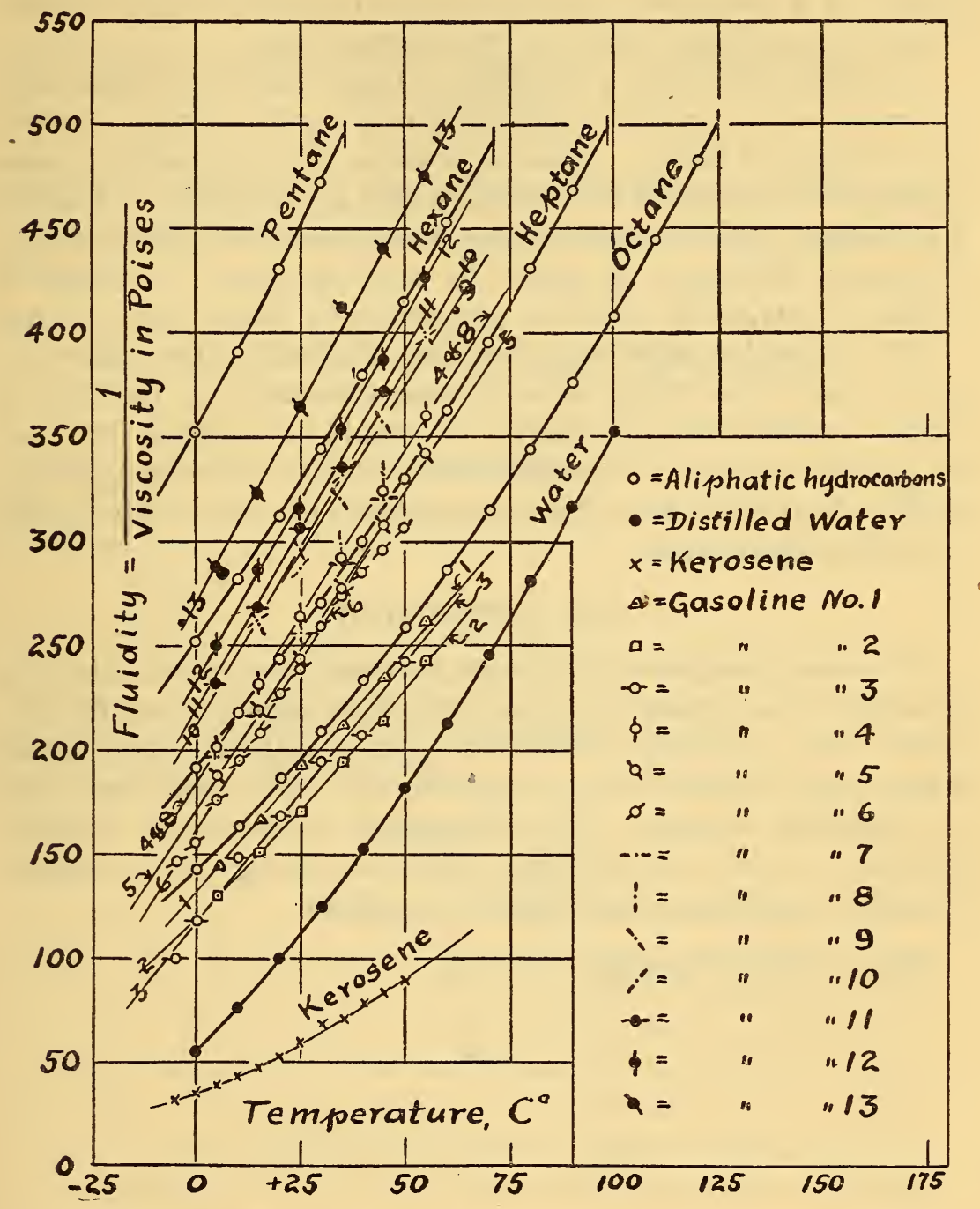

FIG. 4.-Temperature-fluidity curves of gasolines and other liquids

of Bingham and Harrison. ${ }^{17}$ The figure shows that kerosene has a lower fluidity or greater viscosity than water. Ordinary commercial gasoline, as in samples Nos. 2 and 3, has about the same fluidity as octane. The curve for sample No. 7 was omitted for 
the sake of clearness as it would approximately coincide with that for heptane. Most of the aviation gasolines, Nos. 4 and 8 to I 2 . ares hown to be more fluid than heptane and less fluid than hexane Since the temperature-fluidity relation for these gasolines is determined by a practically straight line, their fluidity would be determined by specifying values at two temperatures.

It appears from Fig. 4 that fluidity might serve as an important criterion of the quality or suitability of a gasoline where volatility is an important factor. It seems probable that the fluidity is more closely connected with the volatility than is the density. The test for fluidity, while it does not give the information obtained by a fractional distillation in regard to the homogeneity or range of boiling points of the fuel, is a comparatively simple test to make.

Fig. 4 does not show any indication of a bend in the calibration curves due to the critical velocity being exceeded, but fluidities in Table 7 marked with an asterisk (*) should be accepted with caution, both on account of possible trouble due to the critical velocity and to the possible error due to evaporation of such volatile liquids at high temperatures.

\section{CONCLUSION}

The usual method of judging the volatility or suitability of a gasoline by the density is only a rough approximation, and fluidity, which may be easily determined with a suitable viscosimeter, might prove, either alone or in conjunction with other tests, to be a preferable criterion. The Ubbelohde viscosimeter, designed primarily for use with kerosene, serves well enough for a commercial determination of the fluidity of gasoline.

Washington, December 20, I9I8. 